\title{
Advancing teacher knowledge of effective argumentation pedagogy
}

\section{Progressão do conhecimento docente na pedagogia da argumentação efetiva}

\author{
Shirley Simon $\mathrm{PhD}^{1}$ \\ Paul Davies $\mathrm{PhD}^{2}$ \\ Jillian Trevethan ${ }^{3}$
}

\begin{abstract}
This paper provides a discussion of the methodological approach to a research project that builds on previous studies of effective argumentation pedagogy undertaken by one of the authors. In this study, teachers from six schools in a city location are taking part in a one-year project to use new web-based professional development materials to advance their practice in using group discussion and argumentation in science. The teachers attend workshops on planning and organising effective group-work, introducing argument and sustaining small group discussion, and curriculum planning to promote argumentation activity. Between sessions the teachers develop each aspect of pedagogy in their schools. Data are collected from each of the participating schools using teacher survey and interviews to ascertain perspectives on argumentation practice in science, pedagogical strategies used, changes in practice and collaborative working with colleagues in school. The paper focuses on the issues of research design in determining the impact of the workshops.
\end{abstract}

Keywords: argumentation; teacher development; group-work.

${ }^{1} \mathrm{PhD}$ in Science Education. Institute of Education, University of London. E-mail: s.simon@ioe.ac.uk.

${ }^{2} \mathrm{PhD}$ in Evolutionary Biology. Institute of Education, University of London. E-mail: p.davies@ioe.ac.uk.

${ }^{3}$ Masters in Science Education. University of Bedfordshire. E-mail: jill.trevethan@beds.ac.uk. 


\section{RESUMO}

Este artigo traz uma discussão sobre a abordagem metodológica de um projeto de pesquisa que se baseia em estudos anteriores sobre a pedagogia da argumentação eficaz, realizado por um dos autores. Neste estudo, professores de seis escolas estão participando de um projeto, com duração de um ano, para usar novos materiais de desenvolvimento profissionais baseados na internet para a melhoria da sua prática no uso de grupo de discussão e argumentação em ciências. Os professores participam de oficinas sobre planejamento e organização de grupos de trabalho eficientes, introduzindo argumentação e mantendo a discussão em pequenos grupos, e do planejamento de currículos para promover a atividade argumentativa. Entre as sessões, os professores desenvolvem cada aspecto da pedagogia em suas escolas. Os dados são levantados em cada uma das escolas participantes por meio de questionários e entrevistas junto aos professores para averiguar as perspectivas sobre a prática da argumentação em ciência, estratégias pedagógicas utilizadas, mudanças nas práticas e trabalho colaborativo com os colegas na escola. O artigo enfoca questões sobre o delineamento da pesquisa para determinar o impacto das oficinas.

Palavras-chave: argumentação; desenvolvimento docente; trabalho em grupo.

\section{Introduction}

Science education in the UK and elsewhere in the world has traditionally been dominated by the need to teach an established body of scientific knowledge, to prepare students for future study or careers in science, and for demonstrating performance in examinations. In the UK context the introduction of the national curriculum in 1989 perpetuated this trend, not only in secondary school science, but also in primary schools where national testing in science was developed. Yet changes in the English national curriculum in the last decade have placed more emphasis on "How Science Works", and require children to show an awareness of the nature of science as well as knowledge and understanding of its content. This change has occurred alongside recognition of the value of more open styles of pedagogy, known as dialogic teaching (ALEXANDER, 2005), that have been shown to have effective outcomes for children's reasoning and learning generally, including those set in science contexts that focus on children's talk in the classroom (MERCER; DAWES; WEGERIF; SAMS, 2004). In response to these developments much research in recent years (in the UK and globally) has 
focused on the use of small group discussion and argumentation in the teaching of science (ERDURAN; JIMÉNEZ-ALEIXANDRE, 2008; KHINE, 2011). The use of argumentation activities can help children to develop and articulate their reasoning by providing opportunities to take stances justified with evidence, and to evaluate evidence that is used to support or refute different scientific claims. Thus, the ability to reason can be developed alongside an awareness of how scientific knowledge has become established through the appropriate use of argumentation activities.

Research conducted by Simon and her colleagues has now resulted in many Continuing Professional Development (CPD) programmes based on a curriculum development called IDEAS (OSBORNE; ERDURAN; SIMON, 2004) including small-scale projects with secondary teachers (SIMON; MALONEY, 2006; SIMON; JOHNSON, 2008; SIMON; RICHARDSON; AMOS, 2011). Yet research evidence continues to show that certain aspects of teaching argumentation and adopting dialogic approaches remain challenging for many teachers of all age groups (OSBORNE; MacPHERSON; PATTERSON; SZU, 2011). There is a need to produce specific professional development tools that will help teachers to address these challenges, that will reach a much wider audience of teachers, and that will provide a basis for professional development programmes that can build in sufficient time for sustained changes in practice.

Learning to teach argumentation involves ways of interacting with students to scaffold processes such as justification of claims and counter-argument (SIMON; ERDURAN; OSBORNE, 2006). From 12 years of ongoing research in this area, three key aspects of argumentation pedagogy have consistently been shown to present challenges for teachers. The planning and organisation of small group discussion is the first of these; in spite of much guidance about strategies for working with small groups, where students discuss and evaluate evidence and arguments in science, teachers find it hard to relinquish teacher-led approaches and control of discourse in the classroom. The second challenge is related, as it involves adopting a particular teaching role for introducing and sustaining small group discussion in a way that allows student voice and articulation of reasoning but at the same time is mindful of appropriate scaffolding that can take place to facilitate students' argumentation. The teacher also has to be skilled in conducting plenary discussions within an argumentation lesson to guide the evaluation of accepted scientific explanations. The third challenge for teachers is in the design and interpretation of resources that can be used in argumentation lessons (SIMON; RICHARDSON, 2009); designing or adapting resources for argumentation involves complex interpretation of the purpose of an activity, the science content and possible modes of implementation such as group-work strategies. Thus there are many elements within an activity that need 
to be clear in teachers' minds - the goals, the science, the group-work strategy, the timing and flow of discourse and teacher interjection as the activity proceeds. Establishing all of these pedagogical skills requires practice and guidance.

For professional development to be effective in communities such as school science departments all these practices need to be reflected upon analytically and shared between colleagues working together collaboratively. Research on teacher change has shown reflection and sharing to be essential aspect of learning (HOBAN, 2002). A new approach to developing practice has been adopted in the study reported here that aims to serve two main purposes; the first is that materials and guidance in the form of films and associated tasks can be accessed easily through websites by teachers and professional developers; the second is that clusters of teachers working together within a locality will engage in reflective sharing of professional practice. The study is therefore in two stages; the first is developmental, where argumentation lessons are designed for filming, and workshop tasks are designed around the film clips and lessons; the second is evaluative as teachers within the cluster attend workshops to carry out the tasks and try out their practice in schools. Teachers within the cluster come from linked primary and secondary schools to ease working together collaboratively across the transition. The study therefore has a number of methodological aims:

- How are the films designed to provide a stimulus for professional development in the use of argumentation?

- How are workshops designed to complement the use of film clips?

- In what way do the workshops enable teachers to further their practice?

- How do teachers work with colleagues in school to develop practice using the materials?

\section{Developing materials for CPD}

The first aim of the project is to produce good quality video material that will be accessible via a website and that will be supported by specific professional development tasks. The IDEAS video developed by Simon and colleagues (OSBORNE et al., 2004) provided a useful starting point from which to plan the lessons and film sequences with experienced teachers. The second aim is to work with professional developers in planning three web-based CPD units, so that teachers new to this work to be able to use the web-based resources and teaching strategies and reflect on the outcomes with colleagues. These CPD units 
will be the basis of workshops conducted in a local teachers' centre with clusters of teachers from primary and secondary schools in the area, then reviewed and refined with the experienced teachers and the team.

\section{Films}

Central to the development of the three CPD units is the production of high quality video and audio material that, through carefully editing, can be tailored to support the three main themes of: the planning and organisation of group-work; the teacher's role in introducing argumentation, sustaining small group discussion and conducting a plenary and the design and interpretation of resources within the curriculum. The development of the video material involved the close collaboration between teachers in the schools associated with the project, a specialist film production company and the project leaders. An important focus of this collaboration was that the teachers of the lessons being filmed were fully involved in the planning of the lessons and the subsequent design of the CPD units which are being developed. Filming involved three teachers, teaching separate lessons, in two schools. In the initial stages of the project, two teachers from the same school were filmed and it was anticipated that this would provide all the film footage that was needed. However, the nature of filming in a naturalistic setting is always problematic, so filming of an additional lesson was planned to take place in a different school should the first two films not provide all the material necessary to produce the CPD units. In the event, the additional film was required in order to capture some elements of group-work and argumentation that were absent from the first two films and essential to the successful design of the CPD tasks.

Selecting the three teachers to be involved in this stage of the project involved recruiting from those who had taken part in previous projects related to argumentation. These teachers were well versed in the skills needed to establish and maintain effective argumentation activities in science lessons and were familiar with much of the literature and resources that support this pedagogy. The planning of the lessons to be filmed occurred in two stages; this helped provide some flexibility with the outcome of the exact nature of the lessons and the final video clips. Initially meetings took place with each class teacher to discuss the aims of the project and to initiate the lesson planning process. As it was important to the project that the teachers felt involved in development of the lessons, the meetings focussed on a discussion surrounding the types of group-work activity which would work best, not only for producing the video material for the CPD units but also the specific classes involved and the kinds of resources that would be needed to support the lessons. During these discussions 
a framework for each lesson emerged which allowed the teacher and students to highlight certain aspects of argumentation activities which would make for interesting and informative sequences for the CPD units. Key ideas were raised to prompt and encourage the teachers to think about activities in the lessons which would be useful, for example the teacher grouping the students, students working in small groups and students moving between groups. At the same time, the teachers made suggestions about the lesson design, sometimes specific to the nature of the class or innovative ideas in addition to those of the project leaders; these discussions allowed for the most appropriate lessons to be devised. The two teachers working in the same school were met as a pair, this aided the lesson development process as they were able to share their experiences as well as draw on their own expertise in designing lessons. Following the meetings, the second stage of the process involved the teachers planning their lessons in detail and producing lesson plans, highlighting teacher and student roles and the range of group-work and argumentation strategies they would employ. The plans were then sent to the project team for comment and retained as part of the CPD unit materials.

The film company was chosen because of the experience and expertise of the crew of filming in schools and because of the nature of the quality of the video material they had produced in the past. Being specialists at working in the often cramped and noisy environment of a busy classroom, the film crew were able to make both useful and pertinent suggestions about how the lessons could be designed to allow them to best capture the material required. On the days of filming, the crew were able to advise on suitable layout for the room for ease of movement and signals that the teacher could give to indicate when they were moving to specific areas of the classroom. The teachers identified, and grouped accordingly, students which they felt would be good for the filming to concentrate on. This involved considering students who would be happy to speak, despite the presence of the crew; would discuss their ideas in ways which would match the intended outcomes of the lesson and showed a representative cross-section of the class as a whole. At the start of each lesson the students were introduced to the crew and advised to act as naturally as possibly; a combination of the skill of the crew and their unobtrusive nature and the students' interest in the tasks they were given meant that the students seemed little affected by the filming process. The filming involved whole class teaching, teacher focused and student focused episodes, and teacher-student interactions; ease of filming of these was facilitated through teacher signals to the crew.

Editing of films took place in three stages. Initially a complete transcript of both teacher and student dialogue was made available to the project team. This was particularly valuable for the identification of potential useful footage, 
without the need for the entire film to be edited; both an expensive and time consuming activity. This process then allowed the films to be edited into short sections (ranging from under a minute to a few minutes) of footage that matched the requirements of the three CPD units. The clips were then viewed and detailed notes made focusing on the actions of the teacher and students, dialogue and resource use. To aid this process the themes of the three CPD units were used as a guide to identify footage which would be useful. For example, for the sections of CPD unit two which focus on the teacher's role in introducing argumentation, sustaining small group discussion and conducting a plenary clips were identified where the teacher was talking to the entire class placing them in groups and moving them around the classroom; where the teacher was talking with students or standing back to allow student-student discussion to develop and where the teacher was drawing ideas together at various stages of the lesson, both through talk and also the reinforcement of the resources used and skills developed by the students, during various stages of the lesson. These notes were then used to produce a 'map' of how the clips could be used in the three CPD units. In some cases, one film section proved useful for several of the units, for example footage of how the teachers grouped students is applicable to both the first unit where is shows ideas about organisation group-work and the second unit where it shows one of the roles the teacher plays in introducing argumentation. The final stage consisted of fine editing, particularly of sound, to ensure that each clip was suitable for uploading onto the website. In some cases it was decided to provide subtitles to the film clips, this was important where the sound quality was poor or where the teachers and students were speaking over one another. The final edits were shown to the teachers to gain their approval before any of the material was made publicly available. All filming was conducted after ethical approval was sought from teachers, parents and students.

\section{CPD units}

The aims of the first CPD unit are presented here for exemplification. This is the unit addressing strategies for small group discussion. The aims of the unit are:

1. To explore a range of group-work strategies and to consider how they can be used effectively.

2. To consider how group-work contributes to the processes of argumentation, discussion and scientific understanding.

3. To consider how to develop children's skills to participate effectively in group-work. 
4. To plan how to use the strategies and how to disseminate and work collaboratively with colleagues back in school.

All teacher activities in the units are designed to model student activities, through a process of immersion (LOUCKS-HORSLEY et al., 2003), whereby teachers can gain insights into the way in which an activity unfolds. Sessions where teachers are coming together for the first time often include an "ice-breaker" as a means of getting to know one another. The ice-breaker in this case is a group-work activity called "verbal tennis" in the context of "animals", a strategy seen on film 3, where participants working in pairs share ideas about animals they know but have to listen and link their comment to the first person's comment. This group-work strategy helps students to listen to each other, a basic process needed for successful argumentation (SIMON; ERDURAN; OSBORNE, 2006). The unit proceeds with a combination of activities using different modes of group-work such as pairs to fours, listening triads and envoys, each in different science contexts, and observations of film examples where the strategies are used. Throughout the unit teachers reflect on and discuss the efficacy of the group-work strategies.

The second unit also includes immersion activities focusing on modelling and introducing argumentation, interacting effectively with students whilst they work in small groups, planning and conducting plenary sessions that optimise outcomes, and focusing on talk that encourages argumentation processes, including justification, counter-argument and evaluating argument. The third CPD unit focuses on the design and interpretation of argumentation activities and resources that can be embedded in school curricula on different science topics. Good resources are critical to the success of teaching argumentation, but for optimum use and an awareness of how to adapt existing resources, a critical analysis of the goals of any argumentation activity and the processes involved in using a resource determines effective implementation and can help in future design. Our aim is to help teachers understand activity design and select and use argumentation activities and resources effectively (SIMON; RICHARDSON, 2009).

\section{Evaluating the CPD units}

The CPD units are to be trialled and further developed with teachers working in three workshops; a methodology that is a central part of the project. 
For the CDP units to be effective, and thus used by as wide an audience as possible, having teachers involved in this process was deemed to produce the most helpful material to practising teachers and provide a ready means to begin its dissemination in schools. In addition to this, running face-to-face meetings was seen as both the best and most productive use of time and a way of encouraging critical thought through discussion.

Eight teachers, from six schools in one locality in London, were identified to work on this stage of the project. The teachers were from a range of primary and secondary schools having previously developed relationships with one another. This relationship would benefit the project, both in terms of how the materials may be developed to support the transition between primary and secondary school but also because the teachers may perceive a "common goal" in their work. Recruitment of this group was possible through their previous involvement with one of the authors in a number of CPD courses. For the project to be successful, it was important that the teachers were able to commit to the three separate workshops and also to trialling the materials in their schools throughout the project; these criteria were made clear to the participants before the first workshop commenced. In addition, the teachers were expected to record their evaluations of the materials as and when they used them in school. Inevitably, this type recruitment technique will select for teachers who are particularly interested in argumentation and group-work or have skills in these areas. However, this was considered beneficial, if not essential for this stage of the project, both because of the commitment expected from the participants and also the skills and expertise they would bring to the workshops.

The workshops have been designed to reflect the way the online CPD units will ultimately be structured; this approach was taken as it allows for problems with the initial design of the how the units would be embedded and "unfold" within the website to be considered and it provides information on how best to sequence and order the ideas within each unit in the web pages.

The first workshop is focused on the planning and organisation of group-work, at the start of which the aims of the project and our expectations will be explained to the teachers. They will then be asked to complete a short questionnaire which is designed to establish both their beliefs and ideas about the use and implementation of argumentation in the classroom but also to provide information of their professional background and experiences; these data can then be used to "profile" the teachers involved and provide a comparison on which to base analysis of change in practice at the end of the project; see later. The rest of the workshop will comprise the teachers analysing and evaluating the materials that have been developed for the first CPD unit. This will involve 
watching the video clips of the lessons that were filmed which emphasise how the teachers organise students for effective group-work and reviewing materials the teachers produced that demonstrate their strategies for planning. At the end of the session the teachers will complete an evaluation form commenting on their initial ideas about how effective they feel the CPD materials will be once they are implementing them in school. The teachers will also be given instructions about following up the activities in their schools, for example, to start to planning lessons that support argumentation and group-work and to use different grouping strategies in their classrooms. They will also be asked to record their reflections on, and evaluate these processes in the form of a video diary; this is designed to provide information on how the CPD materials are enacted in schools and how they can be modified before complete dissemination.

The second workshop will be focused on the teacher's role in introducing argumentation, sustaining group discussion and conducting plenaries. This workshop will take a similar form to the first, with the teacher participants reviewing and using the video and paper based materials and considering how these could best be used to support teachers in school. The workshop will also involve a general review of how the materials from the first workshop were used in schools and any additional reflections the teachers have about them; the video diary material will also be collected. During the workshop, each teacher will also be individually interviewed about how they implemented the ideas from the first workshop in their schools; this will focus on what pedagogical strategies they used, if they changed their practice at all and whether or not they disseminated any of the ideas with colleagues. At the end, an evaluation of initial ideas about CPD unit two will also take place.

The focus of the third workshop is the design and interpretation of resources within the curriculum and will take a similar form to the second workshop. However, being more theoretical in nature, this workshop will only involve viewing video material that touches on activity design, essentially the aim is to provide the teacher participants with opportunities to review their specific curricula with a focus on where and how argumentation and group-work activities can be most effectively employed.

\section{Questionnaire}

The initial questionnaire seeks to elicit information about the workshop participants that will inform both the planning of the CPD sessions and provide a means of evaluating the effectiveness of them in enabling the teachers to develop their argumentation practice. 
As the cluster group of teachers is drawn from both primary and secondary schools it is likely that there will be differences in their subject knowledge and confidence. Questions about educational background are designed to create a profile of each teacher taking part in the workshops. Teachers who themselves have been educated in the last decade are likely to have experienced a science education where a comprehension of the nature of science is developed as well as knowledge and understanding. In addition, their experience of science education may indicate the likelihood that teachers themselves have been involved in scientific argumentation. The questions pertaining to age, years of experience and level of science education may give an indication of a teacher's predispositions to the value of teaching about the nature of science.

One of the outcomes of the research is to make recommendations about how the CPD can be implemented. It is likely that a range of recommendations will be needed to personalise the programme for teachers with different prior experiences, confidences and dispositions. An understanding of the starting points of our project teachers and how they make sense of our interventions should enable our advice to be better targeted and therefore more effective. It is important for teachers to share the values of an innovation and be prepared to take risks if transformation of pedagogy is to take place. The questionnaire seeks to find out about the teachers' beliefs about science and how it should be taught, their current practice in relation to group work and willingness to take risks. The teachers' responses will determine to what extent the sessions will need to include specific material designed to challenge attitudes about how science is taught and to promote the value of teaching methods which address the nature of science as well as knowledge and understanding. Analysis of, and differences in, teachers' responses after the CPD interventions will provide a measure of how effective the CPD has been in changing attitudes, competencies, practices and beliefs.

Questions relating to why teachers are participating in the project and what they seek to get out of it are designed to elicit whether their motivation is extrinsic or intrinsic, whether they wish to the CPD to fulfil general needs such as increasing students' engagement or whether they identify a specific need to develop their practice in methods which support their students in developing reasoning or conceptual understanding. Simon and Richardson (2009) have argued in relation to teachers using the IDEAS resources, that task design should address the fact that teachers may not have a clear rationale for argument. Teachers' answers to these questions will therefore need to be taken into account in relation to their engagement in the sessions and evaluation of the workshops. The expectations of teachers in terms of the project at the outset may impact on the validity of their post session evaluations, which are designed to measure the impact of the CPD in developing teachers' expertise in using 
argumentation rather than its effectiveness in supporting the teachers to meet their individual expectations of the project. Experience shows that a mismatch in planned outcomes and teachers' expectations of a course can have a negative impact on teacher evaluation.

\section{Video diaries and interviews}

To provide an accessible way to record each teacher's implementation of argumentation strategies after each workshop, teachers will be provided with flip cameras with which to record their progress and reflections. Teachers will be asked to describe their practice, including which activities they used, including conceptual area, the goals of the activity, the group-work strategies used and their role in classroom interaction. The focus of the video diary will depend on which workshop preceded their practice, but essentially the aim is to capture details of changes in practice, how these were stimulated and how teachers re-evaluate their beliefs and views about group-work and argumentation as they reflect on practice. Teachers will be asked to record whether and how they shared the workshop materials and their own practice with colleagues, and if so what the outcomes are. The focus of the third CPD unit and workshop, on interpretation and design, has implications for how teachers will take their work forwards with colleagues and embed the practice of argumentation within their school curricula.

The video-diaries will be uploaded for analysis at each subsequent workshop, and after the final workshop in school, when each teacher will be visited for a follow-up interview. The final interview will be informed by analysis of the initial questionnaire, the teacher's participation in the workshop, and each video diary. A semi-structured interview will be designed to elicit beliefs, changes in practice and changes in values.

The video-diaries and interviews will also serve to evaluate each CPD unit and refine plans for organising the units on the website for wider dissemination. The website will be launched after evaluation of the CPD units has taken place.

\section{Analysis of teacher data}

Frameworks for analysing the teacher data will be drawn from the work of Bell and Gilbert (1996), Hoban (2002) and Clarke and Hollingsworth (2002). Bell and Gilbert's model (1996) for teacher development includes three domains: personal, professional and social. The first stage of development occurs when teachers begin to see an aspect of their teaching as problematic (personal) and practicing in isolation as problematic (social), so they are motivated to seek out 
and try out new ideas in their practice (professional). As they progress in their development teachers deal with feelings and concerns that come about as they behave differently, for example loss of control, insecurity in subject knowledge, or uncertainty about how to intervene, and begin to change their ideas of what it means to be a science teacher (personal). They also begin to see the value of collaborative ways of working (social) and have confidence to develop their own ideas for classroom practice (professional). Progressing further in their development teachers feel empowered through increasing confidence (personal), they initiate or seek out collaboration (social) and eventually facilitate new kinds of professional development activities (professional). The notion of progression in this model can provide a basis for teachers to evaluate their learning within each domain, and how the three domains are intertwined.

Reflection is also an integral part of Clarke and Hollingsworth's Interconnected Model (2002). This model for change is cyclical, with different entry points within the cycle, where change is seen to occur through the mediating processes of reflection and enactment in distinct domains: the personal domain (teacher knowledge, beliefs and attitudes), the domain of practice (professional experimentation) and the domain of consequence (salient outcomes). In addition, the external domain provides sources of information, stimulus or support. The term "reflection" originates from Dewey's notion of active, persistent and careful consideration where, for example, a reflection and re-evaluation of outcomes can lead to an alteration in beliefs, hence a reflective link between the domain of consequence and the personal domain. A further consideration of the Interconnected Model is the change environment, for example being a member of a school community where colleagues can share the consequences of their experimentation. Teachers can be seen to be stimulated by external sources of ideas which prompt changes in practice (enactment leading to changes in the professional domain), they review their practice and re-evaluate what is important in their student outcomes (reflection leading to changes in the domain of consequence), begin to reconstruct their notion of teaching (the personal domain), which in turn leads to further enactment in the professional domain, a re-evaluation of outcomes and so on.

In our evaluation of the teachers' implementation of the CPD units we anticipate that mapping progression using both models will form the basis of a dialogue between researchers and teachers, and amongst teachers, which enables them to recognize the continuous nature of their own learning and the processes through which it is mediated.

Our analysis will also draw on the insights of Hoban (2002) who, in arguing for the notion of a professional learning system, identifies conditions that are needed to bring about teacher learning. 
These include:

- A conception of teaching as a dynamic relationship with students and with other teachers where there is uncertainty and ambiguity in changing teaching practice.

- Room for reflection in order to understand the emerging patterns of change.

- A sense of purpose that fosters the desire to change.

- A community to share experiences.

- Opportunities for action to test what works or does not work in classrooms.

- Conceptual inputs to extend knowledge and experience.

- Feedback from students in response to ideas being tried.

An evaluation of whether or not these conditions for learning are present in the context of our teachers will enable us to predict sustainability of practice. As Hoban points out, on its own, each condition is unlikely to sustain teacher learning; it is the combination of conditions that is important. Moreover, sufficient time is also needed for practice to become embedded and sustained.

\section{Discussion}

The analysis of teacher change using data sources as teachers attend workshops and trial the units will add to our increasing understanding of the challenges presented by implementing argumentation practices, and of how to guide and support teachers as they engage in further professional development.

The outcomes of this work will be three web-based CPD units that include films and tasks for teaching argumentation that will enhance the use of dialogic practice. The experienced teachers who help to develop these units have an opportunity to enhance their own practice through their engagement in the project, and to advance curriculum development within their own schools. The cluster teachers are able to share the units with colleagues in their schools as these are developed. They will also be able to plan for continuity of practice across the transition from primary to secondary. The web-based materials will reach a wide audience of teachers so will provide the means of sustaining the project in the future and of helping to enable and facilitate the type of school to school support which is set to become the model of CPD as central funding to other sources of professional development may be reduced. 


\section{REFERENCES}

ALEXANDER, R. Towards Dialogic Teaching. New York: Dialogos, 2005.

BELL, B.; GILBERT, J. Teacher development: A model from science education. London: Routledge Falmer, 1996.

CLARKE, D.; HOLLINGSWORTH, H. Elaborating a model of teacher professional growth. Teaching and Teacher Education, v, 18, p. 947-967, 2002.

ERDURAN, S.; JIMÉNEZ-ALEIXANDRE, M. P. Argumentation in Science Education: Perspectives from Classroom-Based Research. Dordrecht: Springer, 2008.

HOBAN, G. Teacher learning for educational change. Buckingham, UK: Open University Press, 2002.

KHINE, M.S. (Ed.). Perspectives on Scientific Argumentation: Theory, Practice and Research. Dordrecht: Springer, 2011.

LOUCKS-HORSLEY, S.; LOVE, N.; STILES, K.; MUNDRY, S.; HEWSON, P. Designing professional development for teachers of Science and Mathematics. Thousand Oaks, CA: Corwin Press, 2003.

MERCER, N.; DAWES, L.; WEGERIF, R.; SAMS, C. Reasoning as a scientist: ways of helping children to use language to learn science. British Education Research Journal, v. 30, n. 3, p. 359-377, 2004.

OSBORNE, J. F.; ERDURAN, S.; SIMON, S. The IDEAS Project. London: King's College London, 2004.

; MacPHERSON, A.; PATTERSON, A.; SZU, E. Introduction. In: KHINE, M. S. (Ed.). Perspectives on Scientific Argumentation: Theory, Practice and Research. Dordrecht: Springer, 2011.

SIMON, S.; ERDURAN, S.; OSBORNE, J. Learning to teach argumentation: research and development in the science classroom. International Journal of Science Education, v. 28 , n. 2-3, p. $235-260,2006$.

; JOHNSON, S. Professional learning portfolios for argumentation in school science. International Journal of Science Education, v. 30, n. 5, p. 669-688, 2008.

; MALONEY, J. Learning to teach "ideas and evidence" in science: a study of school mentors and trainee teachers. School Science Review, v. 87, n. 321, p. 75-82, 2006.

; RICHARDSON, K. Argumentation in School Science: breaking the tradition of authoritative exposition through a pedagogy that promotes discussion and reasoning. Argumentation, v. 23, n. 4, p. 469-493, 2009. 
SIMON, S.; DAVIES, P.; TREVETHAN, J. Advancing teacher knowledge of effective...

; AMOS, R. The Design and enactment of argumentation activities. In:

KHINE, M. S. (Ed.). Perspectives on Scientific Argumentation: Theory, Practice and Research. Dordrecht: Springer, 2011.

Texto recebido em 28 de novembro de 2011.

Texto aprovado em 20 de dezembro de 2011. 